\title{
High-temperature Behaviour of New Fe-Al-Si Alloy Produced by Powder Metallurgy
}

\author{
Pavel Novák, Kateřina Nová, Tomáš Vanka, Filip Průša
}

Department of Metals and Corrosion Engineering, University of Chemistry and Technology Prague, Technická 5, 16628 Prague, Czech Republic. E-mail: Panovak@vscht.cz.

\begin{abstract}
This work describes properties of newly developed Fe-Al-Si alloy for high-temperature applications. This alloy is a material composed of $\mathrm{FeAl}$, FeSi a $\mathrm{Fe}_{3} \mathrm{Al}_{2} \mathrm{Si}_{3}$ intermetallic compounds, which was prepared by powder metallurgy using mechanical alloying and spark plasma sintering. The oxidation resistance at the temperatures of 800 and $1000{ }^{\circ} \mathrm{C}$ was described, as well as the mechanical properties up to $700{ }^{\circ} \mathrm{C}$. During oxidation, the alloy covers by aluminium oxide layer, which protects it against further oxidation. Concerning the mechanical properties, the yield strength and ultimate compressive strength increase in the temperature interval of $400-500{ }^{\circ} \mathrm{C}$.
\end{abstract}

Keywords: iron aluminide; iron silicide; powder metallurgy; high temperature

\section{Introduction}

Bulk intermediary phases of nickel, iron or titanium with aluminium are modern materials for high-temperature applications. They are characterized by lower density and significantly improved thermal stability as compared with common iron or nickel alloys $[1,2]$.

Alloys based on Fe-Al system are cheaper than Ti-Al alloys, used in modern jet engines of the airplanes, but have higher density (approximately $5.7 \mathrm{~g} . \mathrm{cm}^{-3}$ ). These materials based $\mathrm{Fe}_{3} \mathrm{Al}$ or $\mathrm{FeAl}$ ordered phases have very interesting properties such as the excellent chemical resistance to high-temperature oxidation, sulfidation and corrosion in highly oxidizing salts and anomalous temperature dependence of yield stress. In some alloys based on $\mathrm{FeAl}$ and $\mathrm{Fe}_{3} \mathrm{Al}$ phases, the yield stress increases with temperature in a short temperature interval [3].

During the past few decades, powder metallurgy has become an alternative processing route of many materials including also intermetallics. Rapid solidification techniques, such as melt atomization, are problematic due to high melting points of intermetallics [4], extreme reactivity of the melts and poor compressibility and sinterability of the intermetallic powders obtained [5]. Advanced techniques, e.g. hot isostatic pressing, hot extrusion or spark plasma sintering, should be applied for compaction of these rapidly solidified powders [5].

Among the perspective production methods of intermetallics, mechanical alloying has attracted great interest. This method involves preparation of intermetallic compounds from the mixture of pure metals powders by highenergy ball milling, i.e. high energy milling of powder mixtures, where the phase composition changes from individual elemental powders to solid solutions, chemical compounds or amorphous materials [6]. During mechanical alloying, following stages happen: Joining of particles by plastic deformation, crushing of particles, formation of solid solutions and intermetallics [7]. In addition to the simple formation of alloy or intermetallic phase powders, mechanical alloying produces ultra-fine grained or even nanocrystalline powders due to severe plastic deformation during the process.

In this work, high temperature mechanical properties and oxidation resistance of FeAl20Si20 alloy (in wt. \%) prepared by mechanical alloying and spark plasma sintering was studied.

\section{Experimental}

FeA120Si20 alloy (in wt. \%) was prepared by the combination of ultra-high energy mechanical alloying and subsequent spark plasma sintering. Mechanical alloying was carried out in planetary ball mill (Retsch PM 100 $\mathrm{CM}$ ) under following conditions, optimized in our previous paper dealing with the synthesis of intermetallics [6]:

- milling duration: $240 \mathrm{~min}$,

- change of rotation direction each $30 \mathrm{~min}$,

- rotation speed: $400 \mathrm{rpm}$,

- atmosphere: argon

- powder batch: $5 \mathrm{~g}$

- ball-to-powder weight ratio: 70:1.

- initial components: $\mathrm{Fe}, \mathrm{Al}$ and $\mathrm{Si}$ powders of a purity above $99.5 \%$, particle size $<44 \mu \mathrm{m}$.

Microstructure of the alloy was studied by an Olympus PME3 light microscope after etching by modified Kroll's reagent $\left(5 \mathrm{ml} \mathrm{HNO}_{3}, 10 \mathrm{ml} \mathrm{HF}\right.$ a $85 \mathrm{ml} \mathrm{H}_{2} \mathrm{O}$ ).

Mechanical properties of the SPS-consolidated material were by determined by the means of hardness. Compression tests were carried out using LabTest 5.250SP1-VM universal loading machine (produced by LaborTech) at following temperatures: room temperature, 400, 500, 600 and $700{ }^{\circ} \mathrm{C}$ with the initial deformation rate of $0,001 \mathrm{~s}^{-1}$. Thermal stability was evaluated by the hardness measurement and microstructure observation after annealing at 800 and $1000{ }^{\circ} \mathrm{C}$ for $400 \mathrm{~h}$.

Isothermal oxidation tests were carried out at 800 and $1000{ }^{\circ} \mathrm{C}$ in air. Oxidation rate was determined from weight gains caused by the oxide formation on the surface of thermally exposed samples. In the oxidation tests, the samples were heated continuously in alumina crucibles for 100, 200, 300 and $400 \mathrm{~h}$, followed by air-cooling.

\section{Results and discussion}

Microstructure of the FeAl20Si20 alloy is composed of iron silicides particles $\left(\mathrm{Fe}_{3} \mathrm{Si}, \mathrm{FeSi}\right)$ in a matrix of $\mathrm{Al}_{2} \mathrm{Fe}_{3} \mathrm{Si}_{3}$ ternary phase, see Fig. 1 . The size of silicide particles does not exceed $5 \mu \mathrm{m}$. Their geometry is almost rounded, which is good for the resulting mechanical properties of the material. 


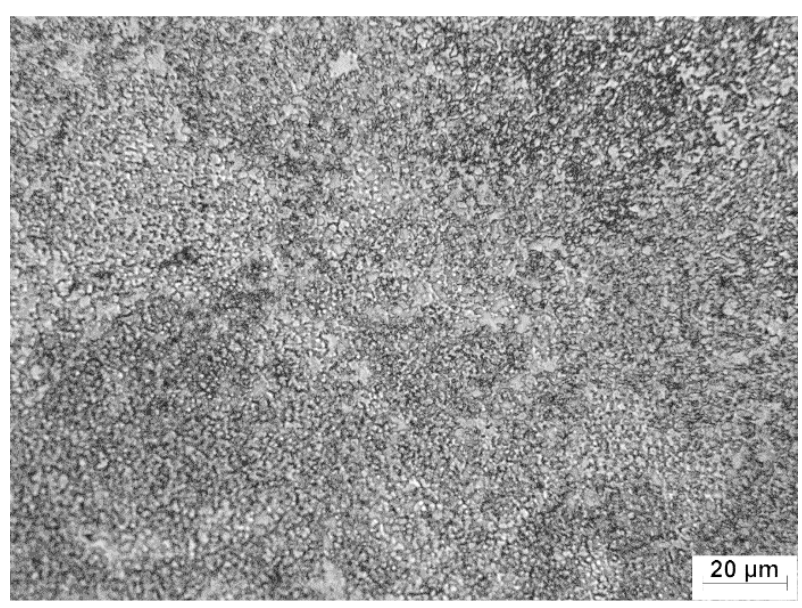

Fig. 1 Microstructure of FeAl20Si20 alloy prepared by mechanical alloying and spark plasma sintering

The yield strength of the alloy at room temperature is $1071 \pm 110 \mathrm{MPa}$, while the ultimate compressive strength reaches $1085 \pm 115 \mathrm{MPa}$. The fact that yield strength is very close to the ultimate compressive strength implies that the material is very brittle. Upon heating, the same behaviour can be observed also at $400{ }^{\circ} \mathrm{C}$. At higher temperatures, larger plasticity was observed. In addition, the yield strength and ultimate compressive strength increase up to 1163 and $1508 \mathrm{MPa}$ at $500^{\circ} \mathrm{C}$, respectively (Fig. 2). This behaviour has been previously observed for aluminide-based alloys [3] and very weakly also in $\mathrm{Fe}_{3} \mathrm{Si}$ iron silicide [8]. In the case of ternary $\mathrm{Fe}_{3} \mathrm{Al}_{2} \mathrm{Si}_{3}$ phase, which forms a matrix of the alloy, the yield strength anomaly has never been reported before.

The anomaly of yield strength and ultimate compressive strength at the temperatures around $500{ }^{\circ} \mathrm{C}$ opens interesting range of applications. These temperatures are common for exhaust valves of diesel internal combustion engines. During normal operation, the temperature reaches approx. $400{ }^{\circ} \mathrm{C}$ and during the cleaning procedure of the filter of solid particles it increases to approx. $500{ }^{\circ} \mathrm{C}$ [9]. These conditions were proved to be optimal for the use of this alloy.

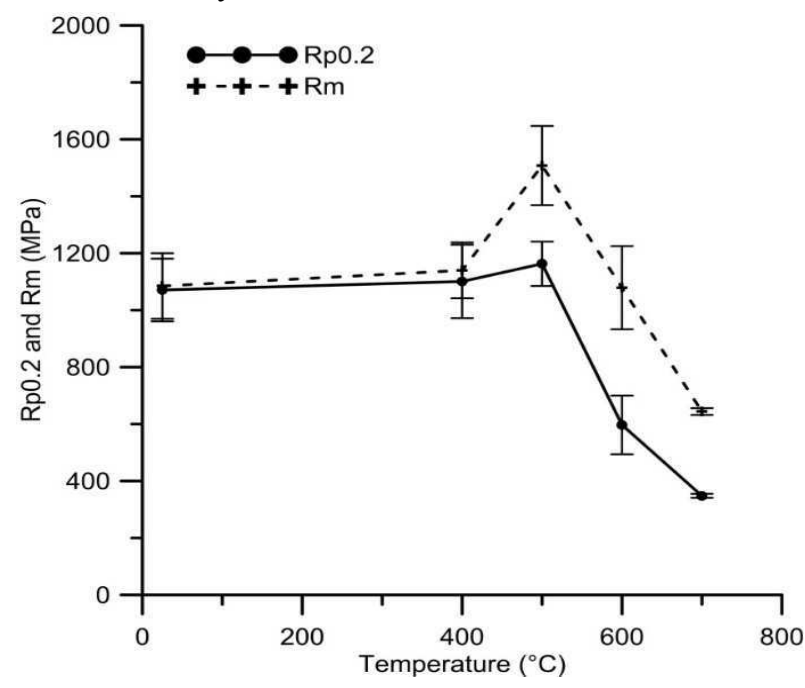

Fig. 2 Temperature dependence of mechanical properties in compression (yield strength Rp0.2 and ultimate compressive strength $\mathrm{Rm}$ ) of FeAl20Si20 alloy

Hardness of the FeA120Si20 alloy vs. duration of annealing at 800 and $1000{ }^{\circ} \mathrm{C}$ is presented in Fig. 3. It can be seen that the hardness does not change significantly after the exposure at both 800 and $1000^{\circ} \mathrm{C}$. This fact was confirmed by observation of microstructure after annealing, because no significant coarsening of silicide particles was observed even after the exposure for $400 \mathrm{~h}$, see Fig. 4.

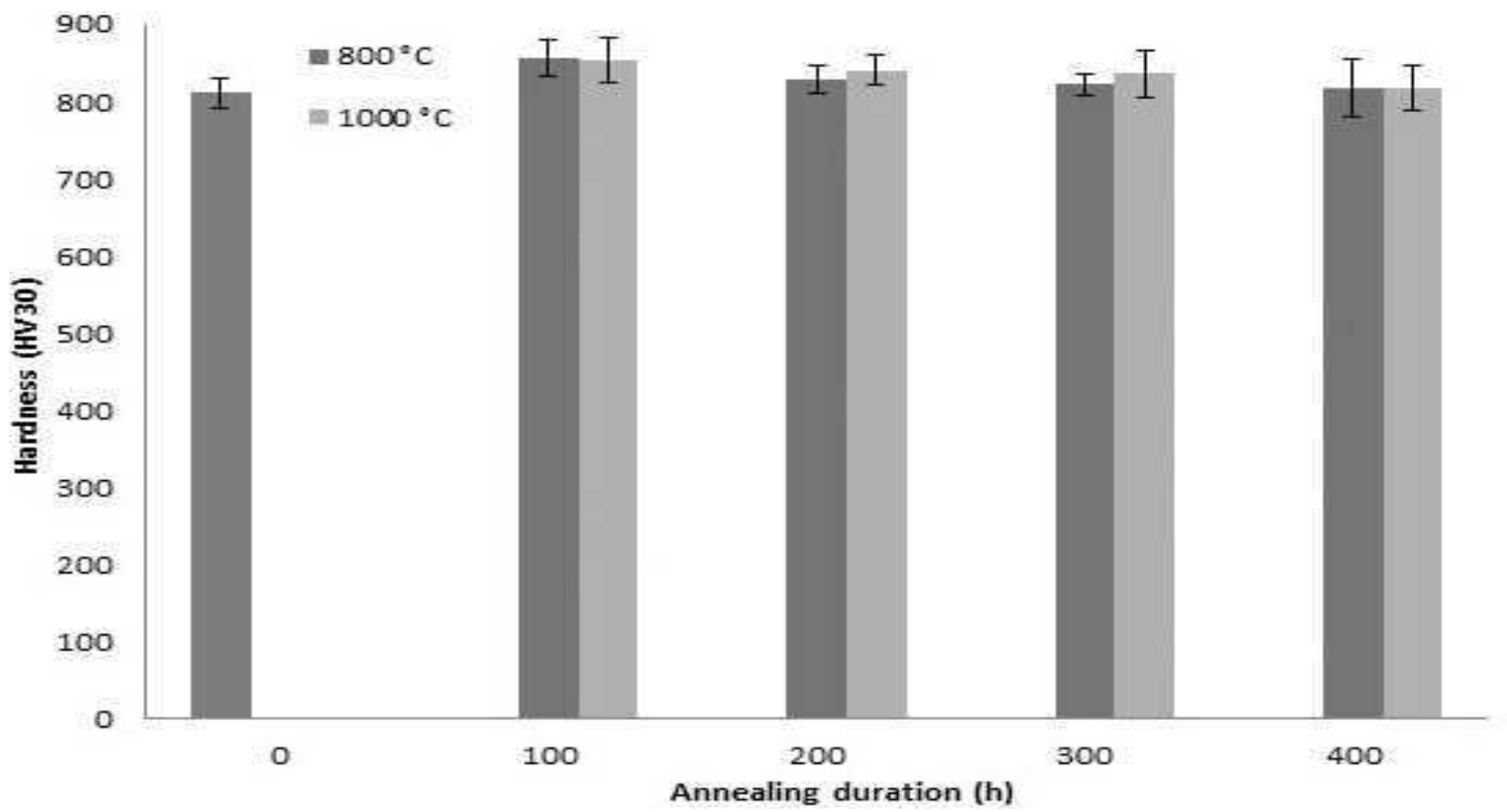

Fig. 3 Hardness of FeAl20Si20 alloy vs. duration of annealing at 800 and $1000^{\circ} \mathrm{C}$ 


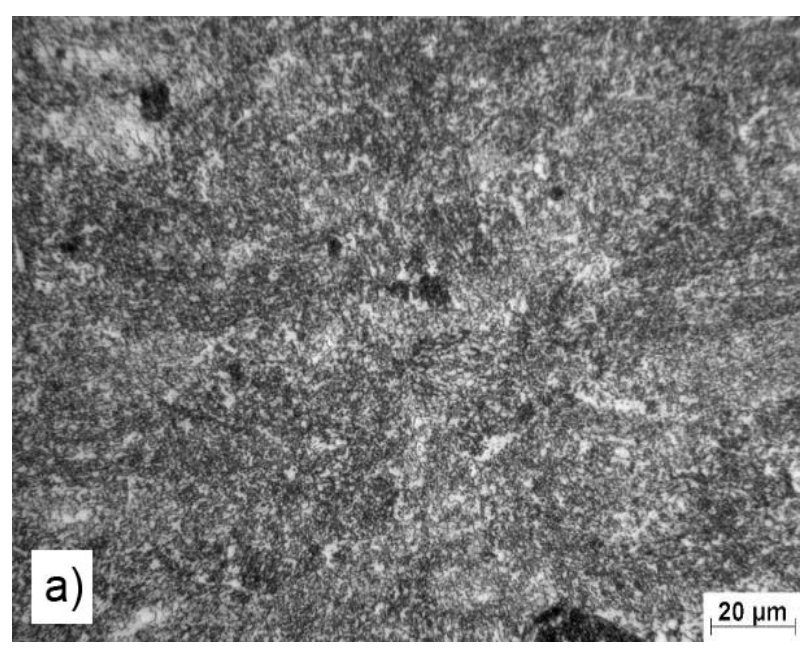

Fig. 4a Microstructure of FeAl20Si20 alloy after annealing at $800{ }^{\circ} \mathrm{C}$ for $400 \mathrm{~h}$

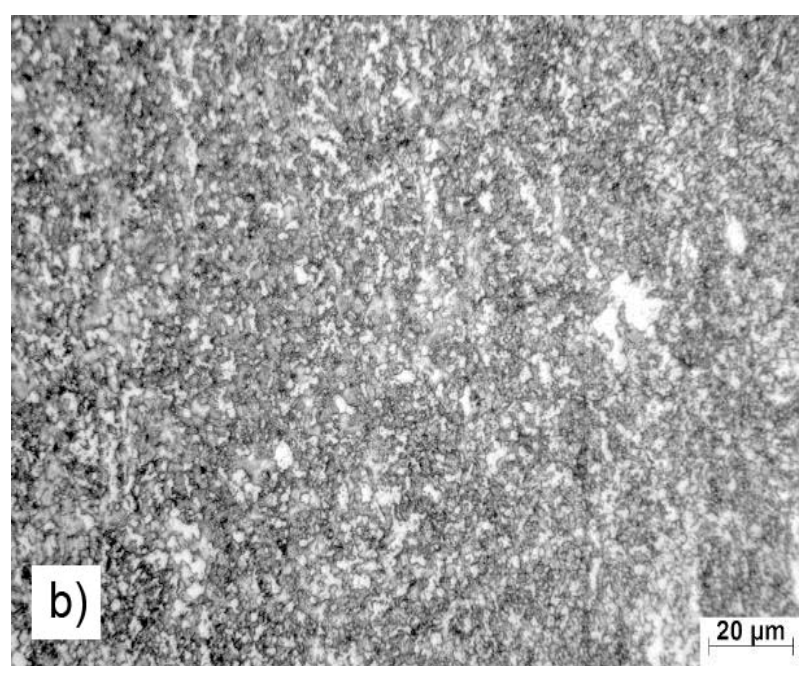

Fig. $4 \boldsymbol{b}$ Microstructure of FeAl20Si20 alloy after annealing at $1000^{\circ} \mathrm{C}$ for $400 \mathrm{~h}$

The oxidation rate of the alloy, represented by weight gains caused by isothermal oxidation, is approx. two times lower at $800{ }^{\circ} \mathrm{C}$ than at $1000{ }^{\circ} \mathrm{C}$ (Fig. 5). The growth of the oxide layer at $800^{\circ} \mathrm{C}$ is linear at the beginning and after $300 \mathrm{~h}$ it follows the parabolic shape, see Fig. 5. It means that the early stages of oxidation are controlled by chemical reaction and therefore it follows the linear law. After reaching certain thickness and compactness of the oxide layer, the oxidation is controlled by the diffusion of oxygen through the oxide layer, thus following the parabolic law. On the other hand, the oxidation at $1000{ }^{\circ} \mathrm{C}$ follows the parabolic law right from the beginning of the oxidation test (Fig. 5). The reason for this behaviour can be found in the phase composition of the oxide layer. At $800{ }^{\circ} \mathrm{C}$ the $\gamma-\mathrm{Al}_{2} \mathrm{O}_{3}$ (cubic) is formed, being nearly immediately transformed to $\delta-\mathrm{Al}_{2} \mathrm{O}_{3}$ (tetragonal or orthorhombic). It induces cracks in the oxide layer and lowers the protective effect of the layer in the initial stage of the oxidation. On the other hand, at $1000{ }^{\circ} \mathrm{C} \alpha-\mathrm{Al}_{2} \mathrm{O}_{3}$ (corrundum, trigonal) is formed, which is stable and compact and therefore it acts as the oxidation barrier right from the beginning of the exposure [10].

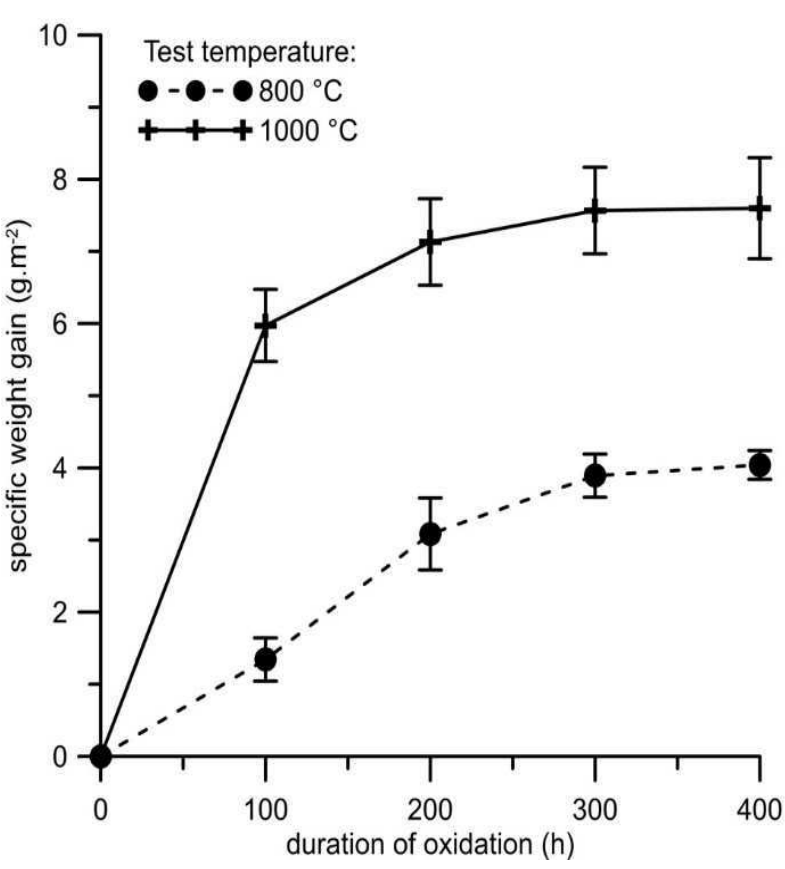

Fig. 5 Dependence of specific weight gain on duration of oxidation at 800 and $1000{ }^{\circ} \mathrm{C}$

\section{Conclusion}

In this work, the FeAl20Si20 alloy (in wt. \%) was prepared by the combination of mechanical alloying and spark plasma sintering. The alloy exhibited very fine structure, composed of silicides $\left(\mathrm{Fe}_{3} \mathrm{Si}\right.$ and $\left.\mathrm{FeSi}\right)$ and ternary phase $\left(\mathrm{Fe}_{3} \mathrm{Al}_{2} \mathrm{Si}_{3}\right)$. The ultimate compressive strength of the alloy was nearly $1100 \mathrm{MPa}$ at room temperature. Due to anomalous behaviour, it increased to approx. $1500 \mathrm{MPa}$ at $500{ }^{\circ} \mathrm{C}$. The FeAl20Si20 alloy exhibits excellent oxidation resistance at 800 and $1000{ }^{\circ} \mathrm{C}$ in the air and excellent thermal stability at these temperatures. Due to superior oxidation resistance and mechanical behaviour at the appropriate temperatures, the material could be applicable in automotive industry for the manufacture of exhaust valves of diesel engines.

\section{Acknowledgement}

This research was financially supported by Czech Science Foundation, project No. 17-07559S.

\section{References}

[1] LEE, D., SANTELLA, M.L., ANDERSON, I.M., PHARR G.M. (2005) Thermal aging effects on the microstructure and short-term oxidation behavior of a cast Ni3Al alloy. In: Intermetallics, Vol. 13, pp. 187-196.

[2] MORRIS, D.G., MUNOZ-MORRIS M.A. (2007) Development of creep-resistant iron aluminides. Materials Science and Engineering A462, pp. 4552.

[3] MORRIS, D.G., MUNOZ-MORRIS, M.A. (2010) A re-examination of the pinning mechanisms responsible for the stress anomaly in FeAl intermetallics, Intermetallics, Vol. 18, pp. 1279-1284. 
[4] MASSALSKI, T.B. (1990) Binary Alloy Phase Diagrams, ASM Int.: Materials Park.

[5] VAN DYCK, S., DELAEY, L., FROYEN, L., BUEKENHOUT, L. (1995) Reactive powder metallurgy of Ni3Si-based alloys. In: Intermetallics, Vol. 3, 309-314.

[6] NOVÁK, P., ŠKOLÁKOVÁ, A., VOJTĚCH, V., KNAISLOVÁ, A., POKORNÝ, P., MORAVEC, H., KOPEČEK, J., KARLÍK, M., KUBATÍK, T.F. (2014) Application of Microscopy and X-ray Diffraction in Optimization of the Production of NiTi Alloy by Powder Metallurgy, In: Manufacturing Technology, Vol. 14, pp. 387-392.

[7] VALALIK, M., NOVÁK, P., KUBATÍK, T.F., VOJTĚCH, D. (2015) Unconventional Method of Preparation Intermetallic Phases Fe-Al by Mecha- nical Alloying in Comparison to Reactive Sintering, In: Manufacturing Technology, Vol. 15, pp. 105-109.

[8] SCHAEFER, H.E., FRENNER, K., WURSCHUM R. (1999) High-temperature atomic defect properties and diffusion processes in intermetallic compounds, In: Intermetallics, Vol. 7, pp. 277-287.

[9] CASTELlanO, J., CHAUDHARI, A., AND BROMHAM, J. (2013) Adaptive Temperature Control for Diesel Particulate Filter Regeneration, SAE Technical Paper 2013-01-0517, doi:10.4271/2013-01-0517.

[10] NOVÁK, P., ZELINKOVÁ, M., ŠERÁK, J., MICHALCOVÁ, A., NOVÁK, M., VOJTĚCH, D. (2011) Oxidation resistance of SHS Fe-Al-Si alloys at $800{ }^{\circ} \mathrm{C}$ in air, In: Intermetallics, Vol. 19, pp. 1306-1312. 